Supporting Information for

\title{
Organic n-Channel Transistors Based on Core-Cyanated Perylene Carboxylic Diimide Derivatives
}

R. Thomas Weitz, ${ }^{*}$ Konstantin Amsharov, Ute Zschieschang, Esther Barrena Villas, Dipak K. Goswami, Marko Burghard, Helmut Dosch, Martin Jansen, Klaus Kern, and Hagen Klauk

R. T. Weitz, Dr. K. Amsharov, Dr. U. Zschieschang, Dr. M. Burghard, Prof. Dr. M. Jansen, Prof. Dr. K. Kern, Dr. H. Klauk

E-mail: t.weitz@fkf.mpg.de

Max Planck Institute for Solid State Research Heisenbergstraße 1, 70569 Stuttgart (Germany)

Dr. E. Barrena Villas, Dr. D. K. Goswami, Prof. Dr. H. Dosch

Max Planck Institute for Metals Research

Heisenbergstraße 3, 70569 Stuttgart (Germany)

Prof. Dr. K. Kern

Institut de Physique des Nanostructures

Ecole Polytechnique Fédérale de Lausanne

1015 Lausanne (Switzerland) 

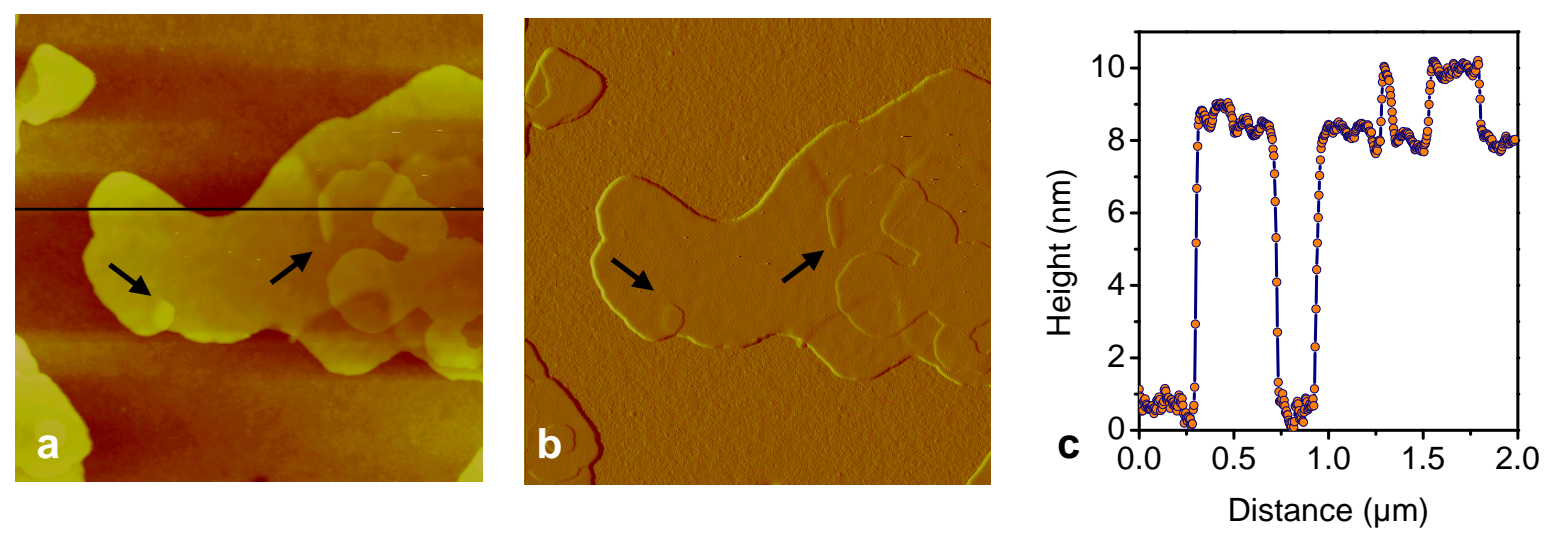

Figure S1 (a) Atomic Force Microscopy (AFM) height and (b) amplitude image (size $2 \times 2 \mu \mathrm{m}^{2}$ ) of an individual island of compound 2 when vacuum deposited with the substrate held at $140^{\circ} \mathrm{C}$ in an area of the substrate that was partially shaded by a clamp during the vacuum deposition. The initial stages of the generation of screw dislocations can be observed (marked by arrows): An advancing front is divided into two traces that form a screw dislocation upon recombination, as described by Schlom et al. ${ }^{1}$ (c) Height profile at the position indicated by the black line in (a).

${ }^{1}$ D. G. Schlom, D. Anselmetti, J. G. Bednorz, R. F. Broom, A. Catana, T. Frey, C. Gerber, H.

J. Guntherodt, H. P. Lang, J. Mannhart, Z. Phys., B: Cond. Mat. 1992, 86, 163 

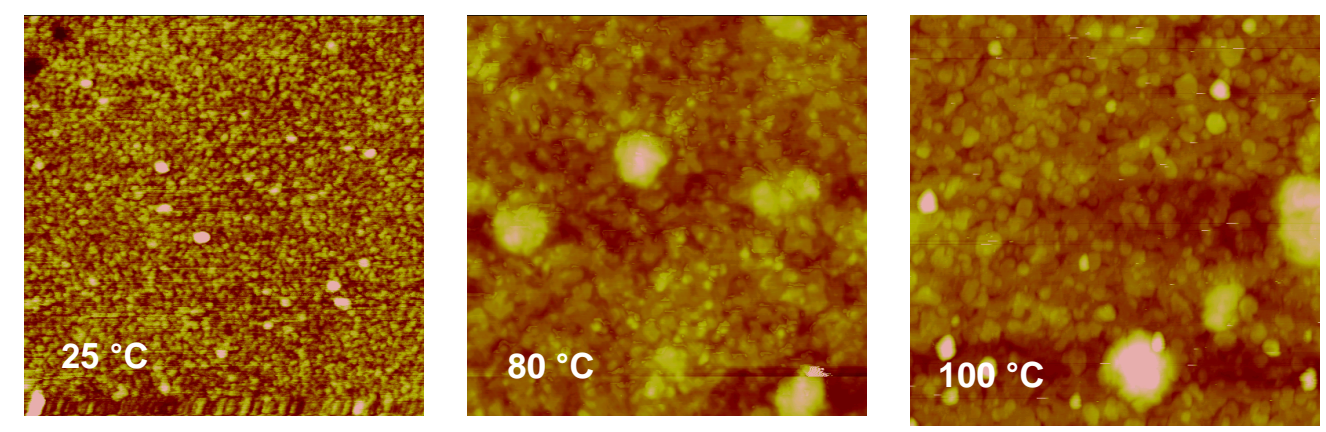

Figure S2 AFM images $\left(2 \times 2 \mu \mathrm{m}^{2}\right)$ of compound 2 deposited at substrate temperatures of $25^{\circ} \mathrm{C}, 80^{\circ} \mathrm{C}$ and $100^{\circ} \mathrm{C}$. 

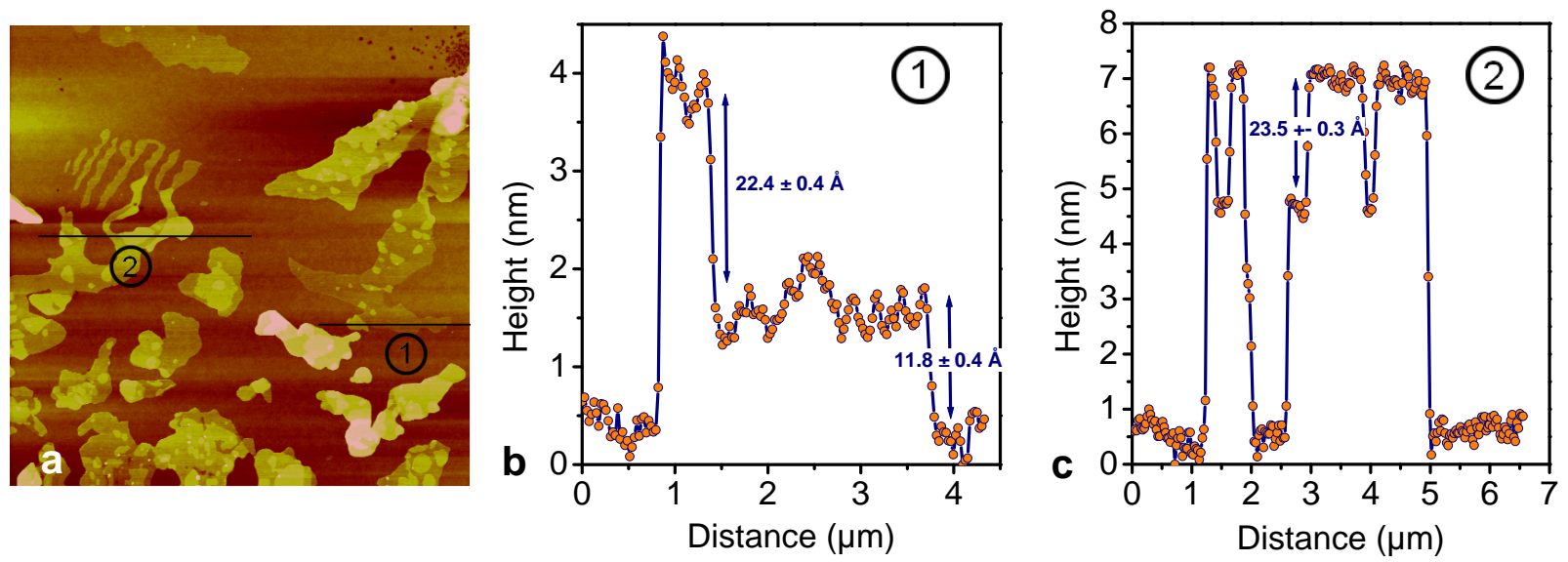

Figure S3 (a) AFM image $\left(13.1 \times 13.1 \mu \mathrm{m}^{2}\right)$ of a region of the substrate that was partially shaded by a clamp during the vacuum deposition, so that individual islands of compound $\mathbf{2}$ deposited at a substrate temperature of $140^{\circ} \mathrm{C}$ can be observed. (b) Scan at position 1 as indicated in (a). A step with a step-height of $11.8 \AA$ can be observed suggesting that the molecules are oriented with their long axis parallel to the substrate. (c) Scan at position 2 as indicated in (a). The step-height is $23.6 \AA$. 

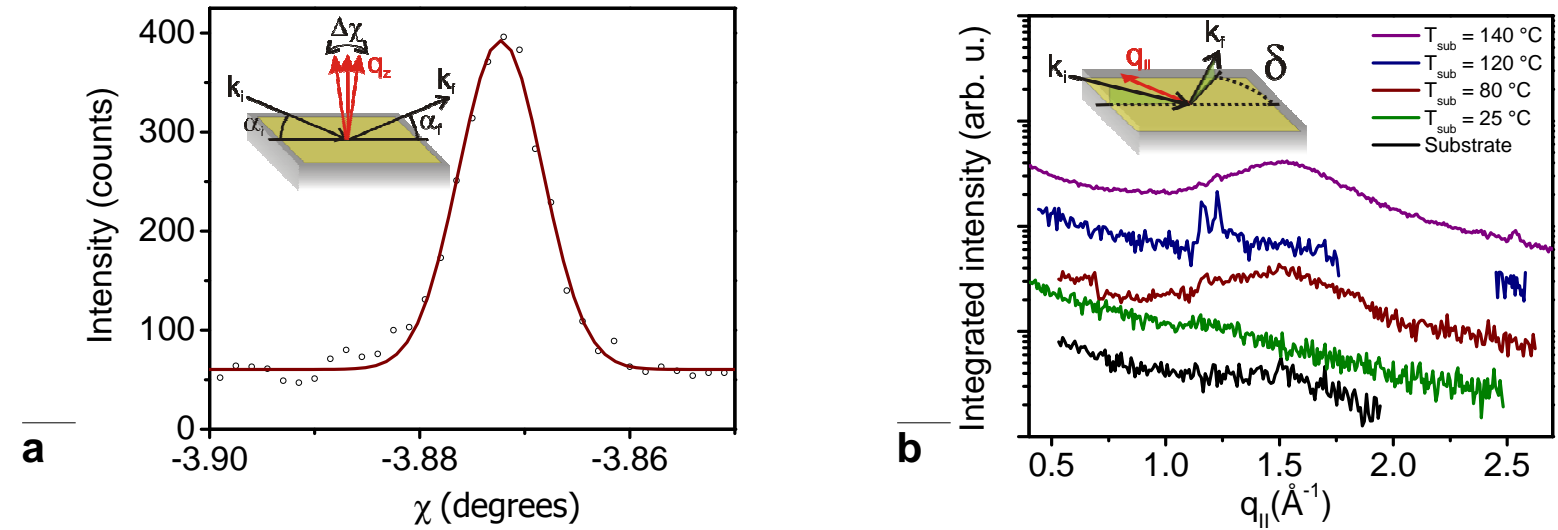

Figure S4 (a) Rocking curve obtained for a film of compound 2 deposited at a substrate temperature of $120^{\circ} \mathrm{C}\left(q=0.68342 \AA^{-1}\right)$. The degree of molecular alignment is excellent, with a mosaicity of $0.008^{\circ}$ estimated from the Full Width at Half Maximum (FWHM) of the rocking curves. The data are shown in black, the fit to the data calculated using the Parratt32 software based on the Parratt algorithm is shown in red. Inset: Out-of-plane scattering geometry used in the experiment.

(b) Grazing Incidence X-Ray Diffraction (GIXD) data obtained for a film of compound 2 deposited at substrate temperatures of $25,80,120$ and $140^{\circ} \mathrm{C}$. In-plane reflections observed for the films deposited at $120^{\circ} \mathrm{C}$ and $140{ }^{\circ} \mathrm{C}$ correspond to an in-plane spacing of $5.39 \AA$ and $5.12 \AA$, respectively. Note that at a reciprocal wave vector of $2.53 \AA^{-1}$ an inplane reflection is seen for the $140^{\circ} \mathrm{C}$ film, but not for the $120^{\circ} \mathrm{C}$ film. In contrast, the reflections at $1.15 \AA^{-1}$ and $1.22 \AA^{-1}$ are observed in both films. This finding supports the hypothesis of the presence of two polymorphs in films deposited at a substrate temperature of $140^{\circ} \mathrm{C}$. Inset: In-plane scattering geometry of the experiment. 

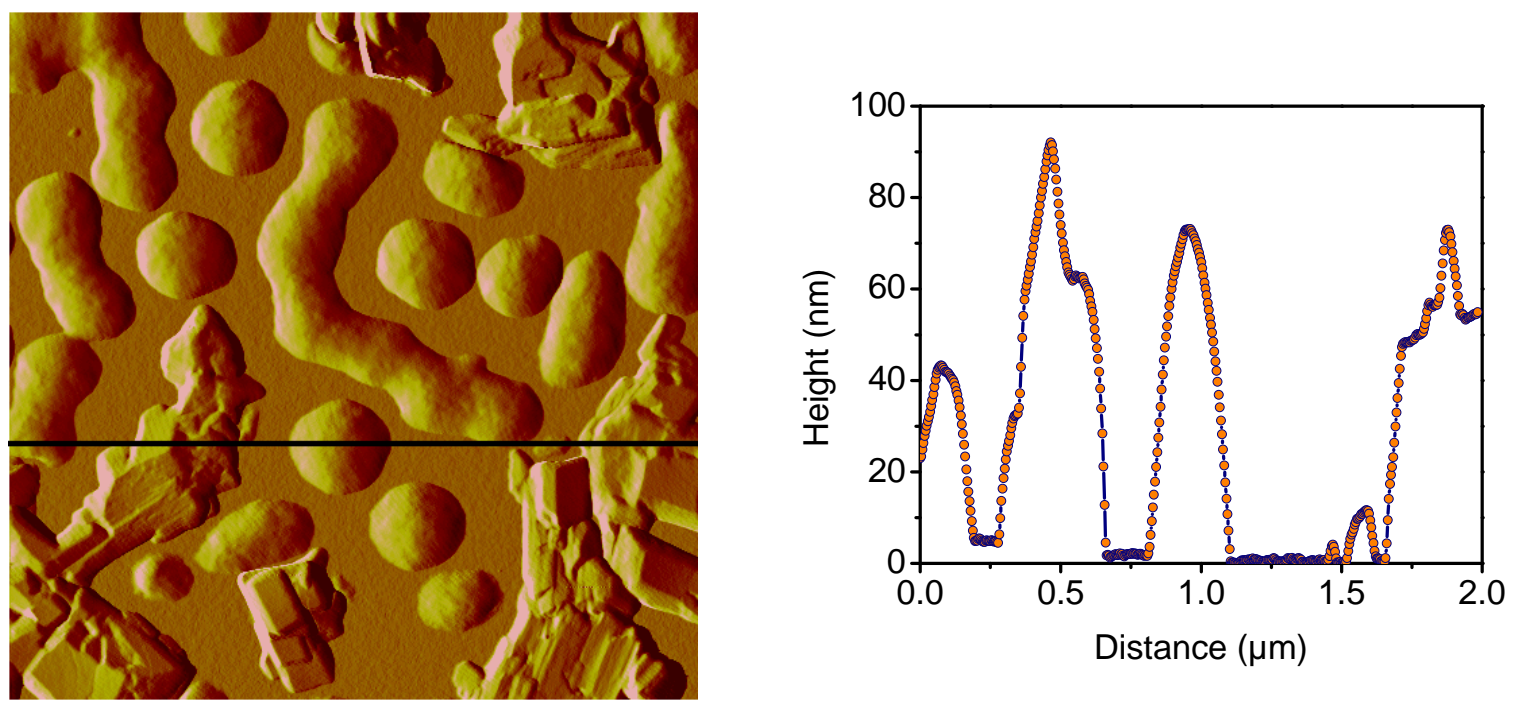

Figure S5: AFM image of compound 1 deposited at a substrate temperature of $100^{\circ} \mathrm{C}$. The film grows in island growth mode. Some islands appear to be amorphous, others appear more ordered with flat terraces. The terraces are not oriented parallel to the substrate. At these high temperatures the molecules seem to have a very low interaction with the underlying substrate and dewet from the surface. Left side: linescan extracted from the corresponding AFM height image at the position indicated by the black line. 

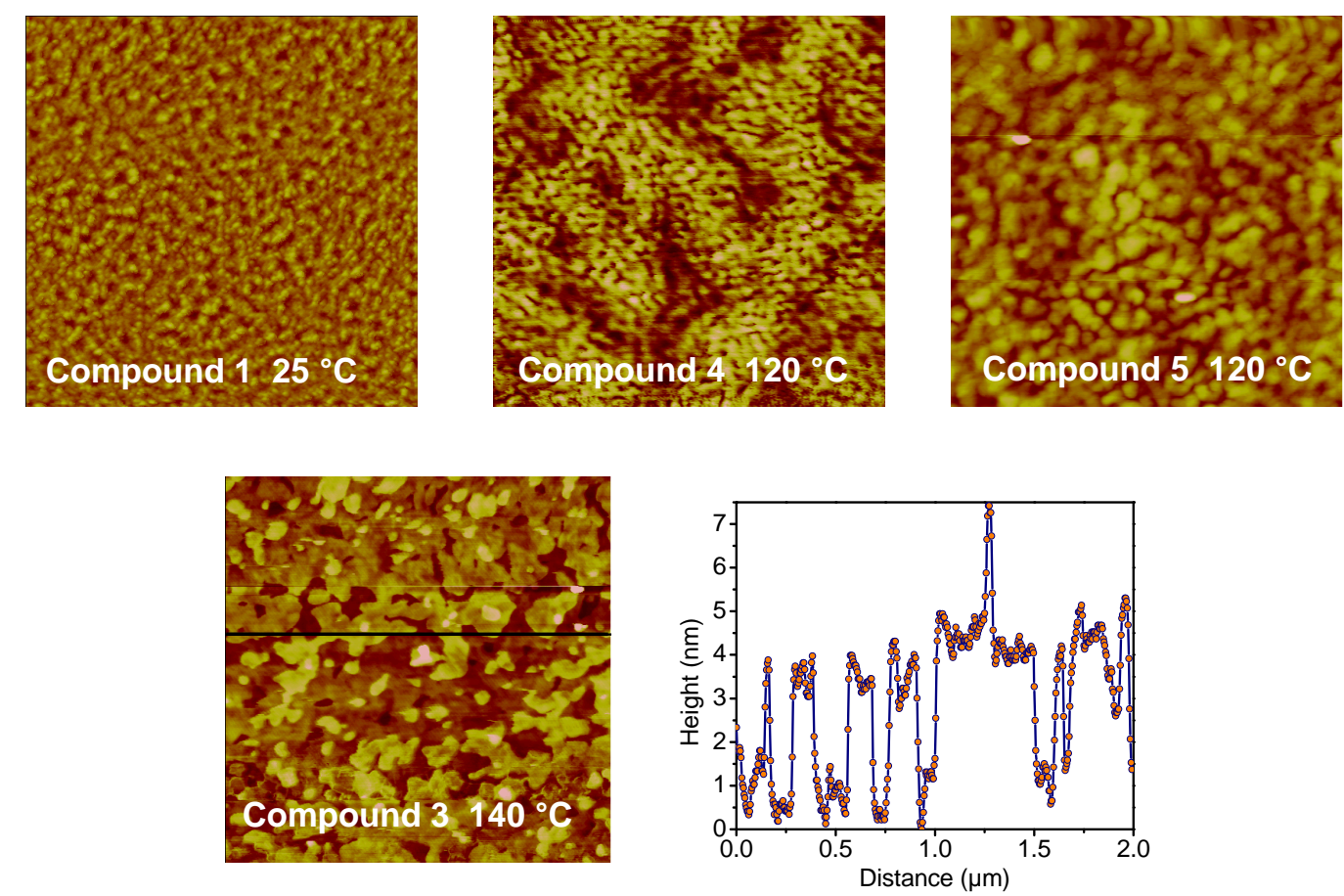

Figure S6: AFM images of compounds 1 and 3-5. The substrate temperature during the deposition, indicated in each image, is the deposition temperature for which the largest FET mobility was obtained. The linescan was extracted from the AFM image of compound $\mathbf{3}$ at the position indicated by the black line. 

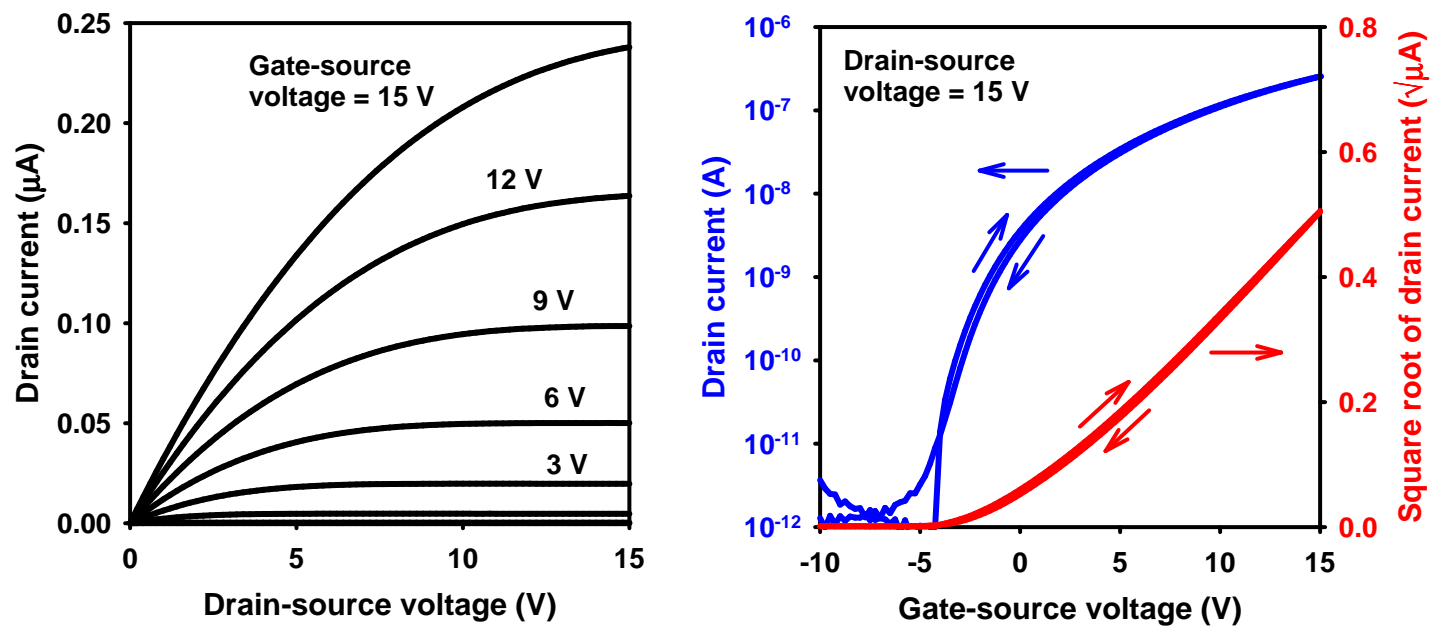

Figure S7 Electrical characteristics of a FET based on compound $\mathbf{3}$ deposited at a substrate temperature of $140^{\circ} \mathrm{C}$. The transistor has a carrier mobility of $0.05 \mathrm{~cm}^{2} / \mathrm{Vs}$. 

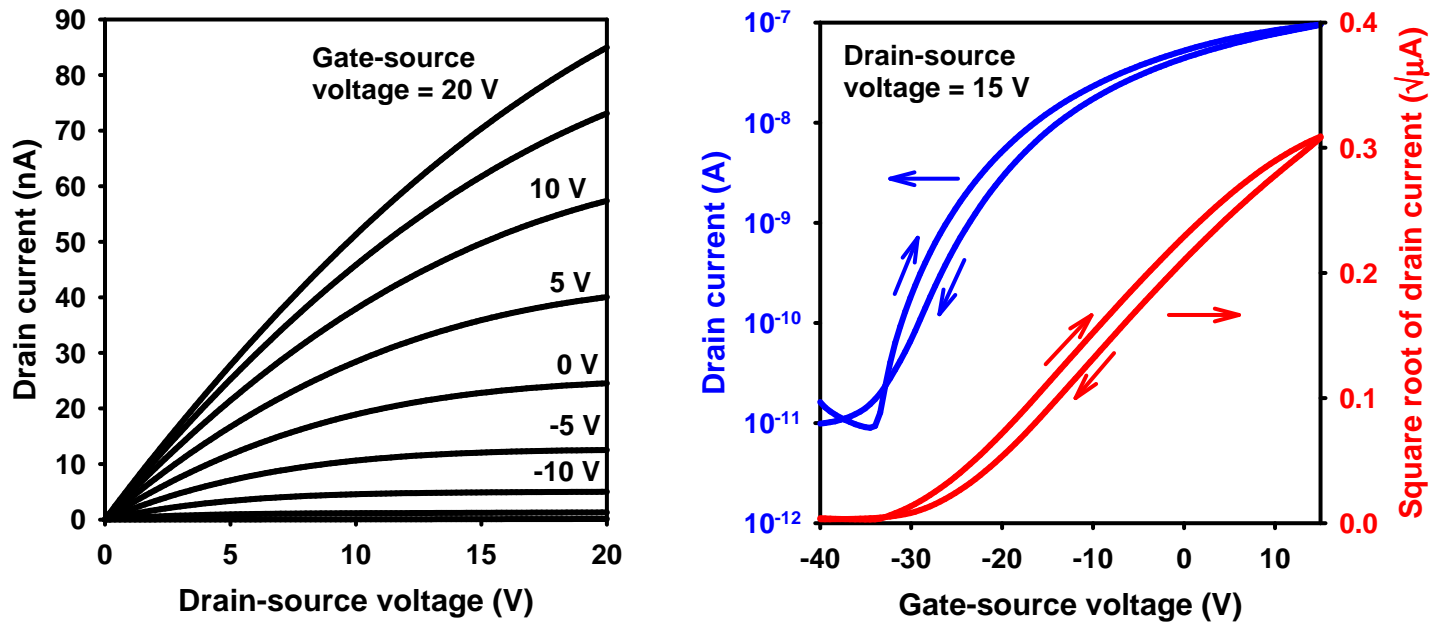

Figure S8. Electrical characteristics of a FET based on compound $\mathbf{4}$ deposited at a substrate temperature of $120^{\circ} \mathrm{C}$. The transistor has a carrier mobility of $0.004 \mathrm{~cm}^{2} / \mathrm{Vs}$. 

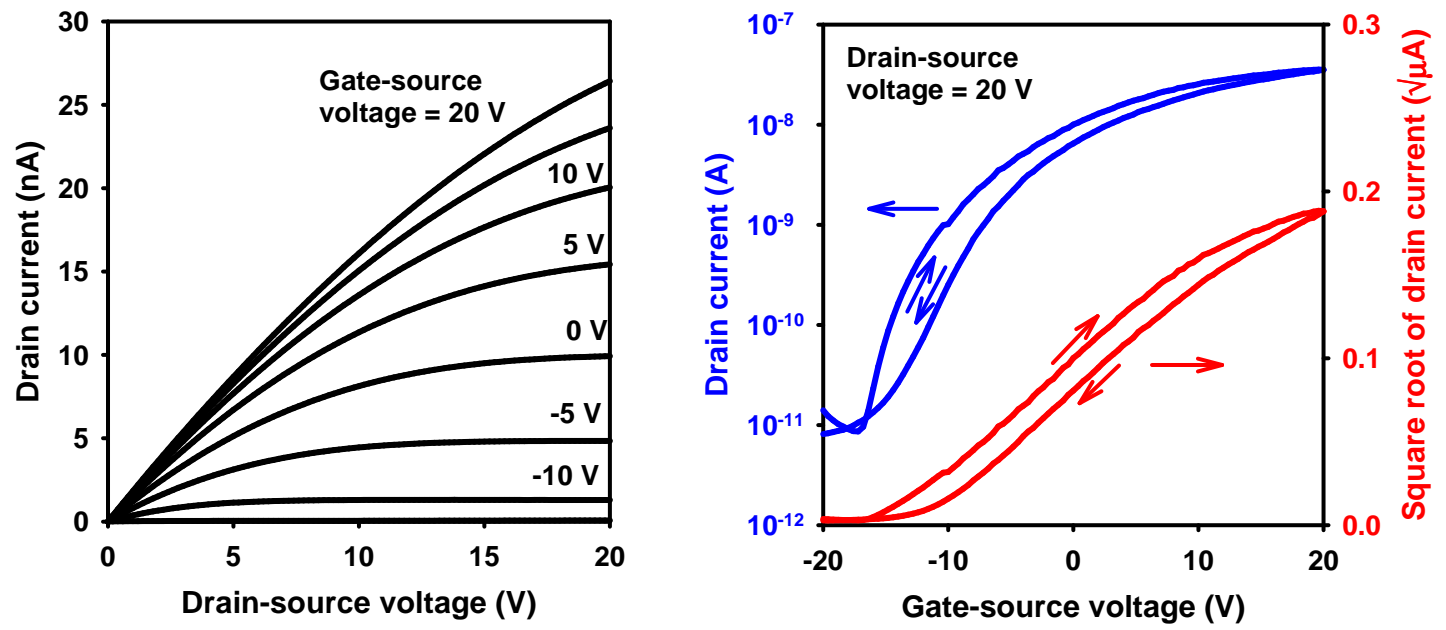

Figure S9. Electrical characteristics of a FET based on compound $\mathbf{5}$ deposited at a substrate temperature of $120^{\circ} \mathrm{C}$. The transistor has a carrier mobility of $0.002 \mathrm{~cm}^{2} / \mathrm{Vs}$. 


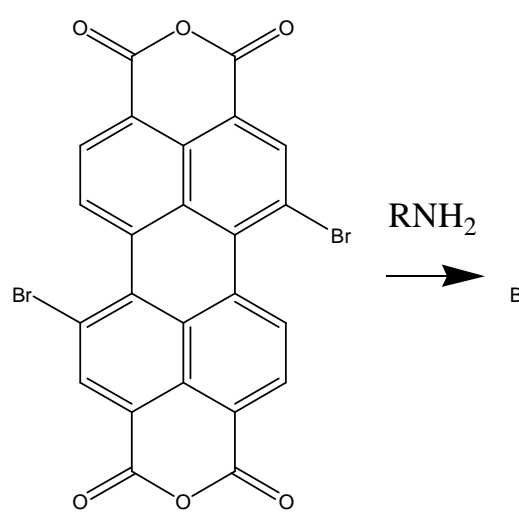

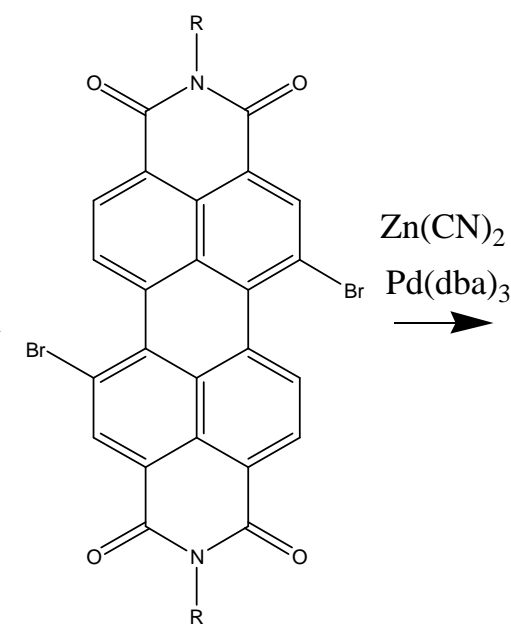

a

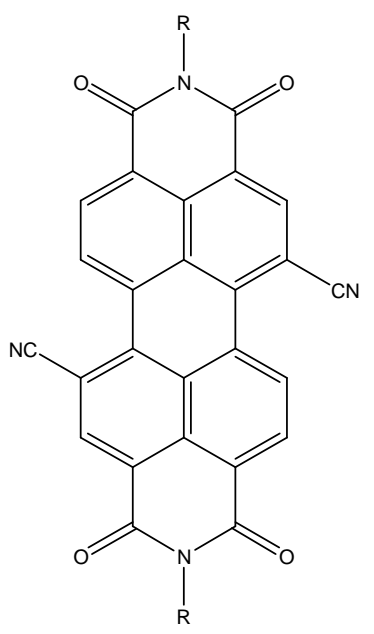

b

Scheme S1: Synthesis route for compounds 1-5. 
Nuclear Magnetic Resonance (NMR) spectra and Laser Desorption lonization-Time of Flight Mass Spectrometry (LDITOF MS) data of all compounds synthesized in this work are presented on the pages 12-21. All pages are arranged the following way:

(top) NMR spectrum, the number of the compound is indicated at the bottom right of each spectrum. The solvent peak is marked with $a *$. (inset) compound of which the NMR was taken.

(bottom) Experimental LDI-TOF MS spectrum. (left inset) calculated MS spectrum (right inset) enlarged view of the experimental LDI-TOF MS spectrum. 


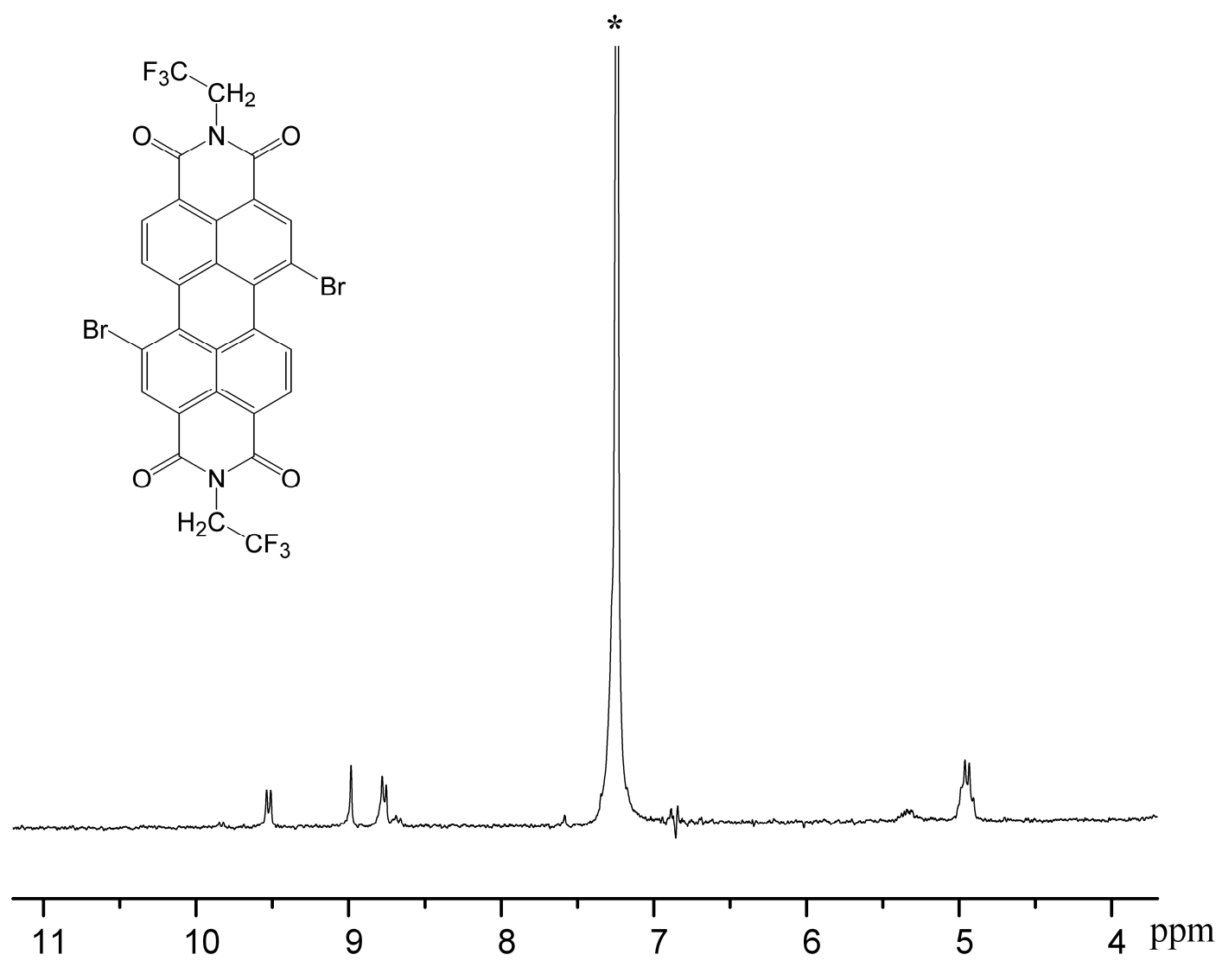

1a. ${ }^{1} \mathrm{H}$ NMR $\left(\mathrm{CDCl}_{3}, 300 \mathrm{MHz}\right)$

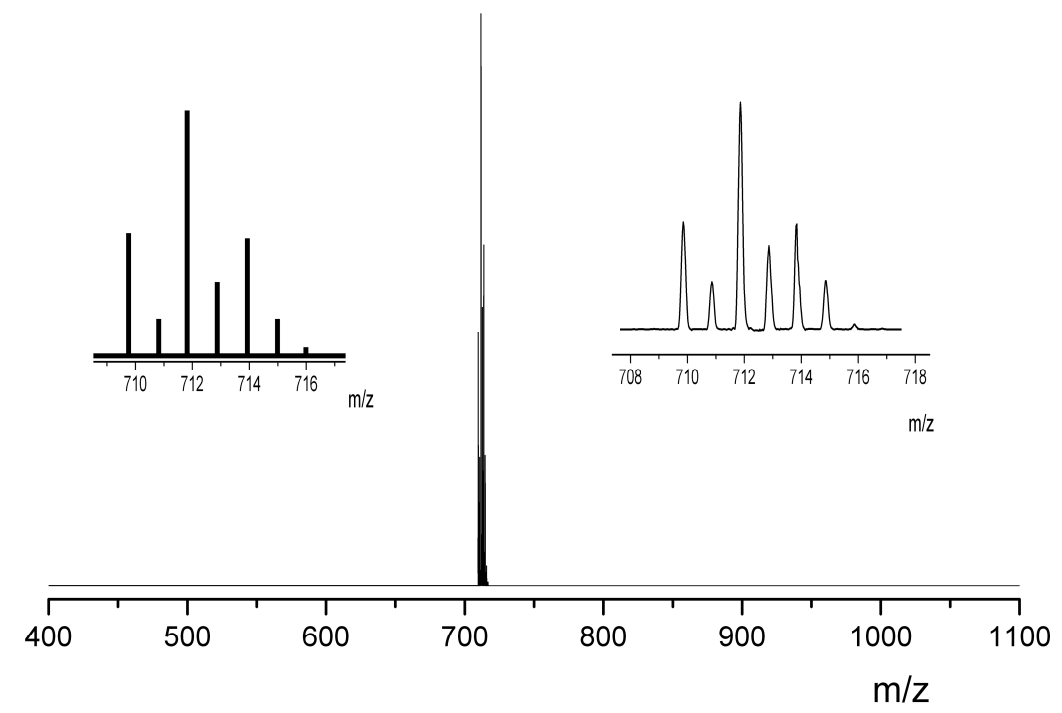



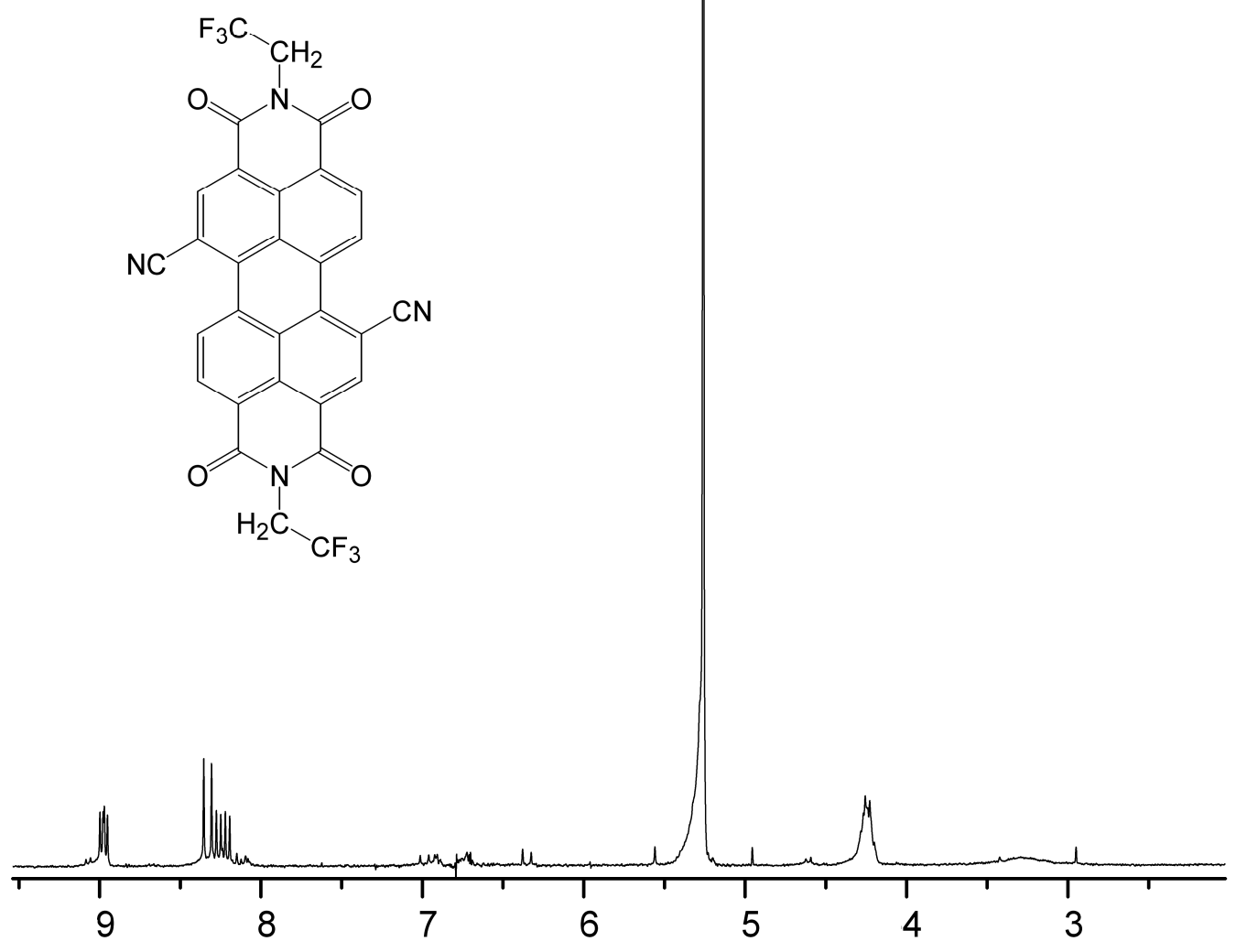

1b. ${ }^{1} \mathrm{H}$ NMR $\left(\mathrm{C}_{2} \mathrm{D}_{2} \mathrm{Cl}_{4}, 300 \mathrm{MHz}\right)$

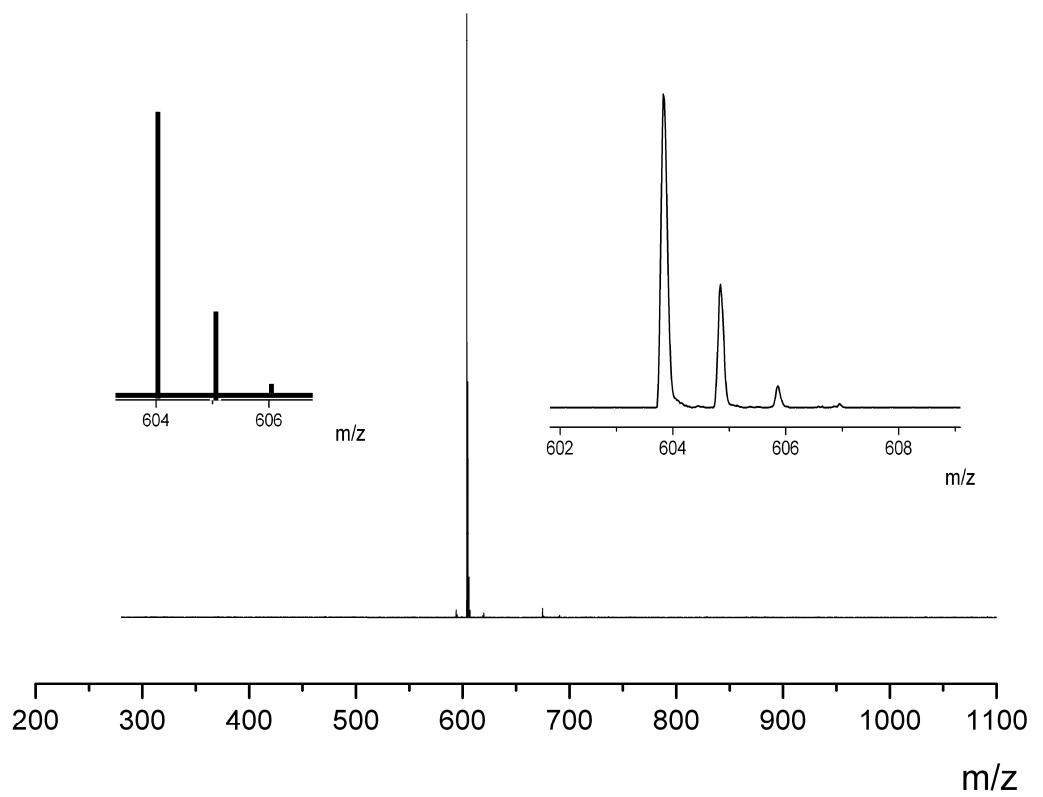




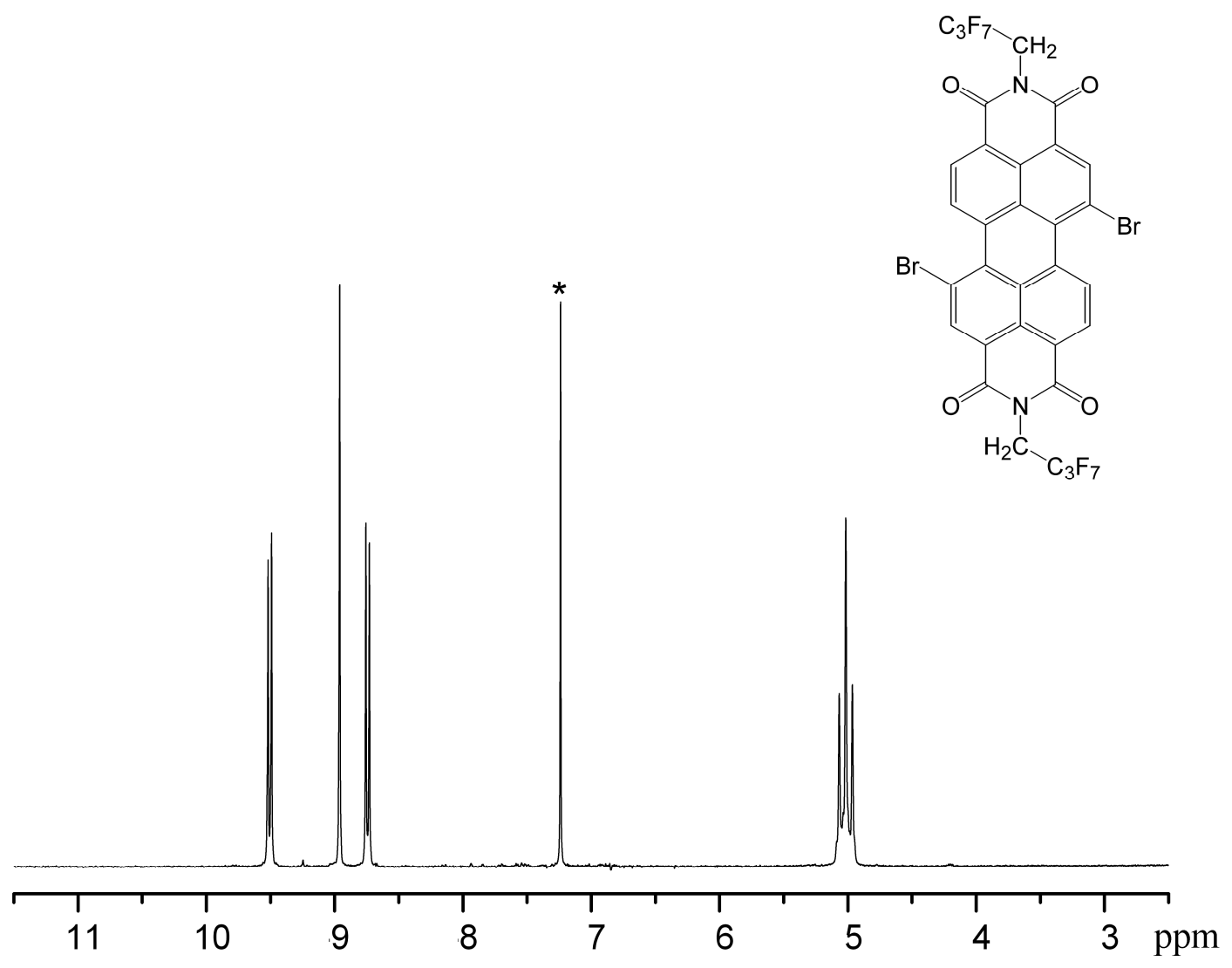

2a. ${ }^{1} \mathrm{H} \mathrm{NMR}\left(\mathrm{CDCl}_{3}, 300 \mathrm{MHz}\right)$

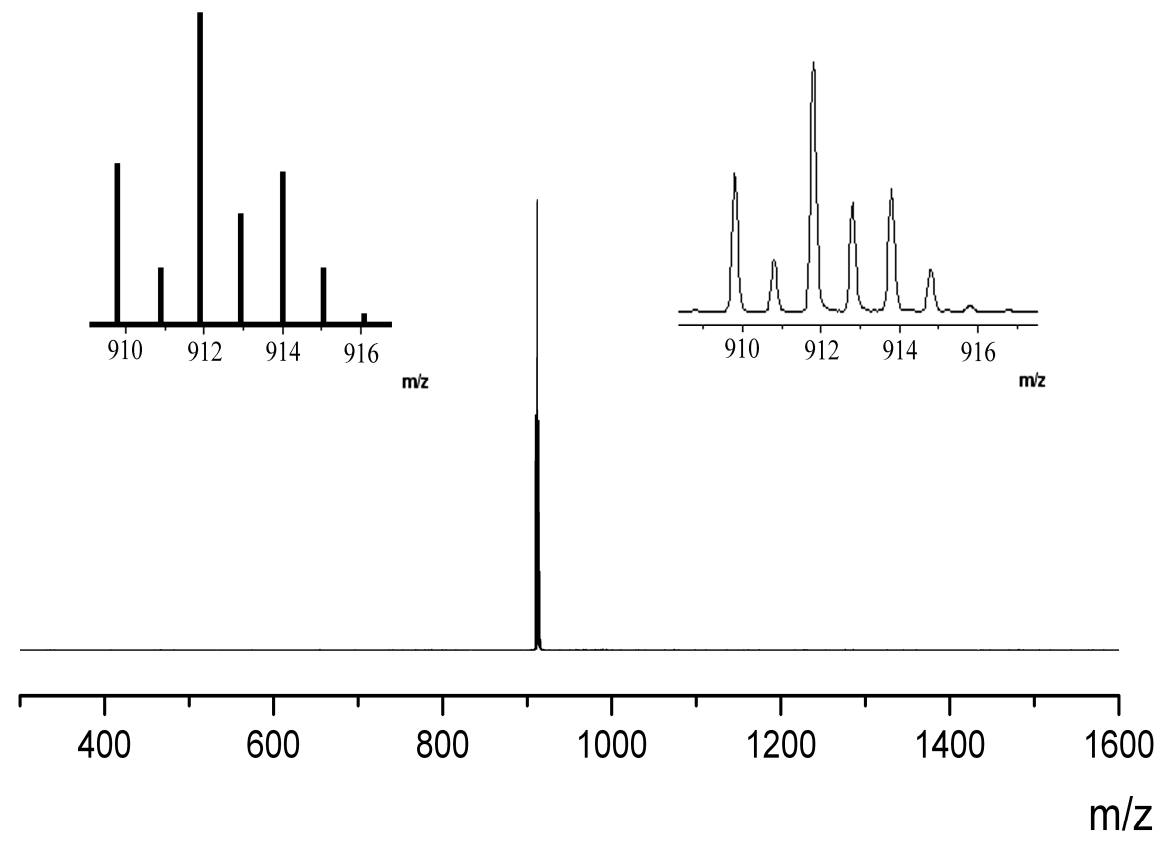




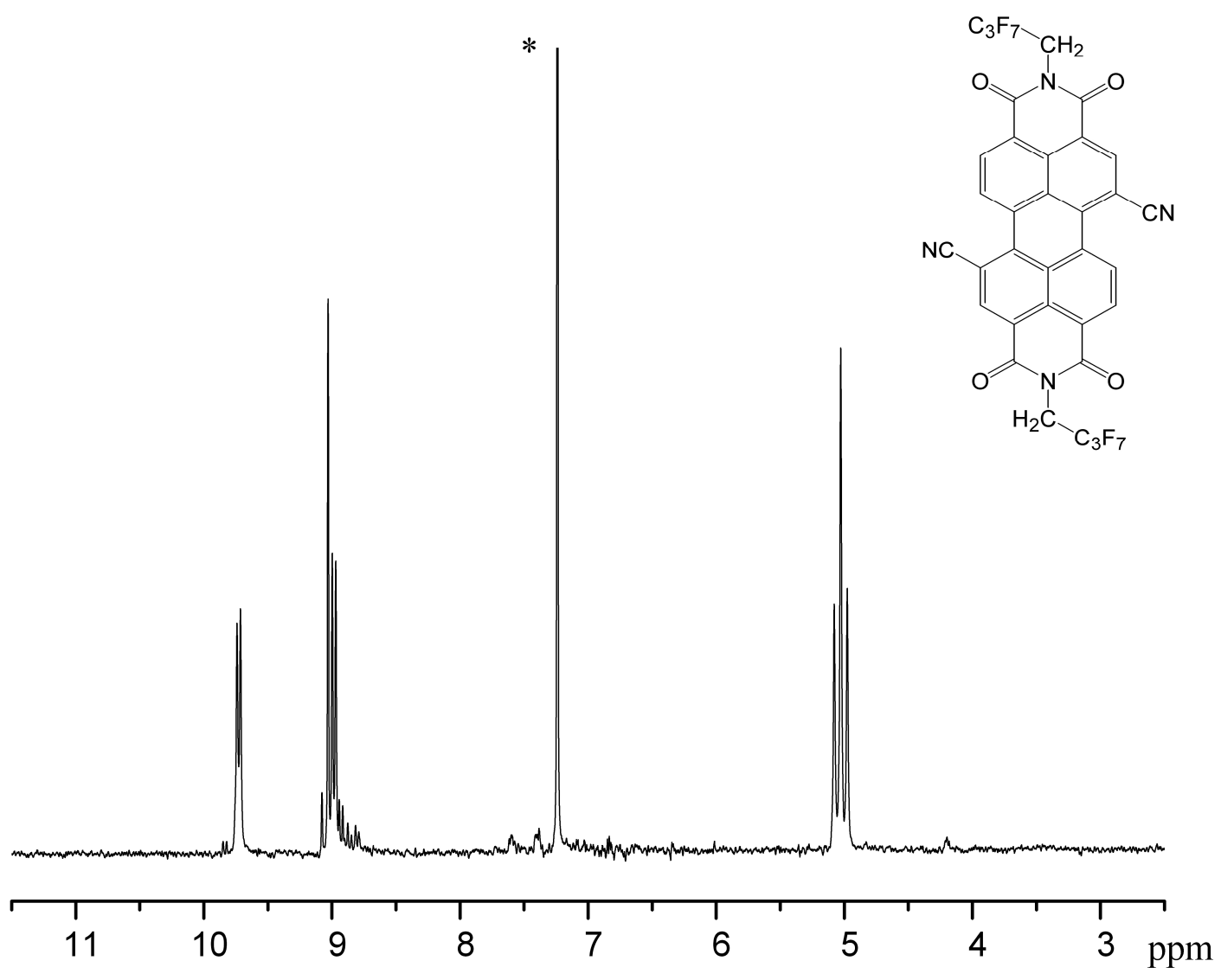

2b. ${ }^{1} \mathrm{H} \mathrm{NMR}\left(\mathrm{CDCl}_{3}, 300 \mathrm{MHz}\right)$

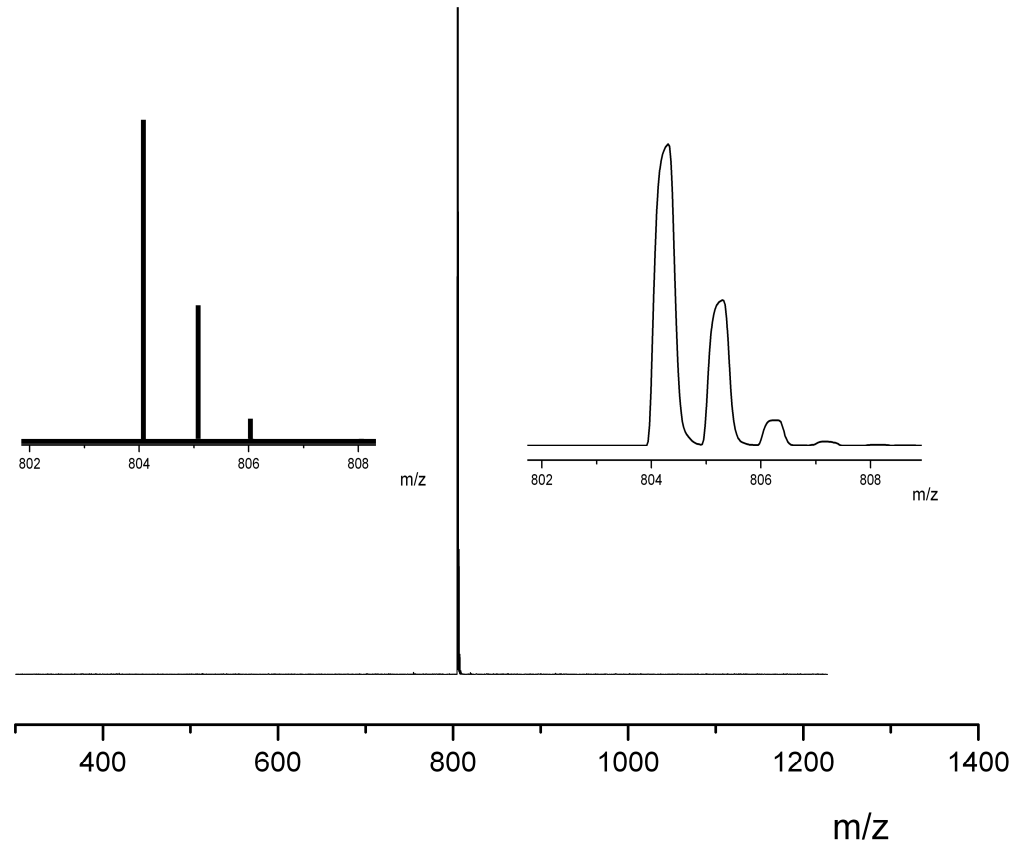




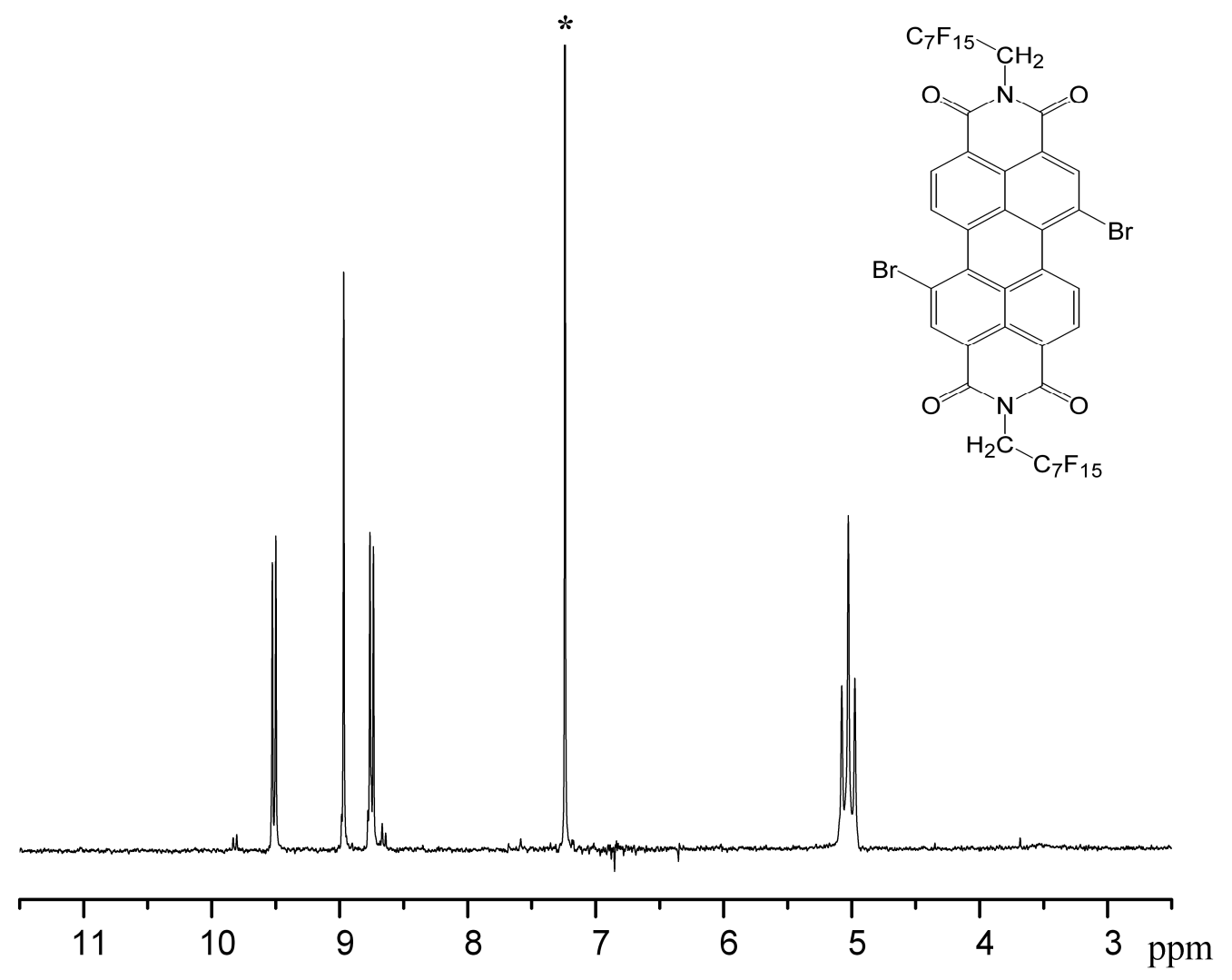

3a. ${ }^{1} \mathrm{H} \mathrm{NMR}\left(\mathrm{CDCl}_{3}, 300 \mathrm{MHz}\right)$

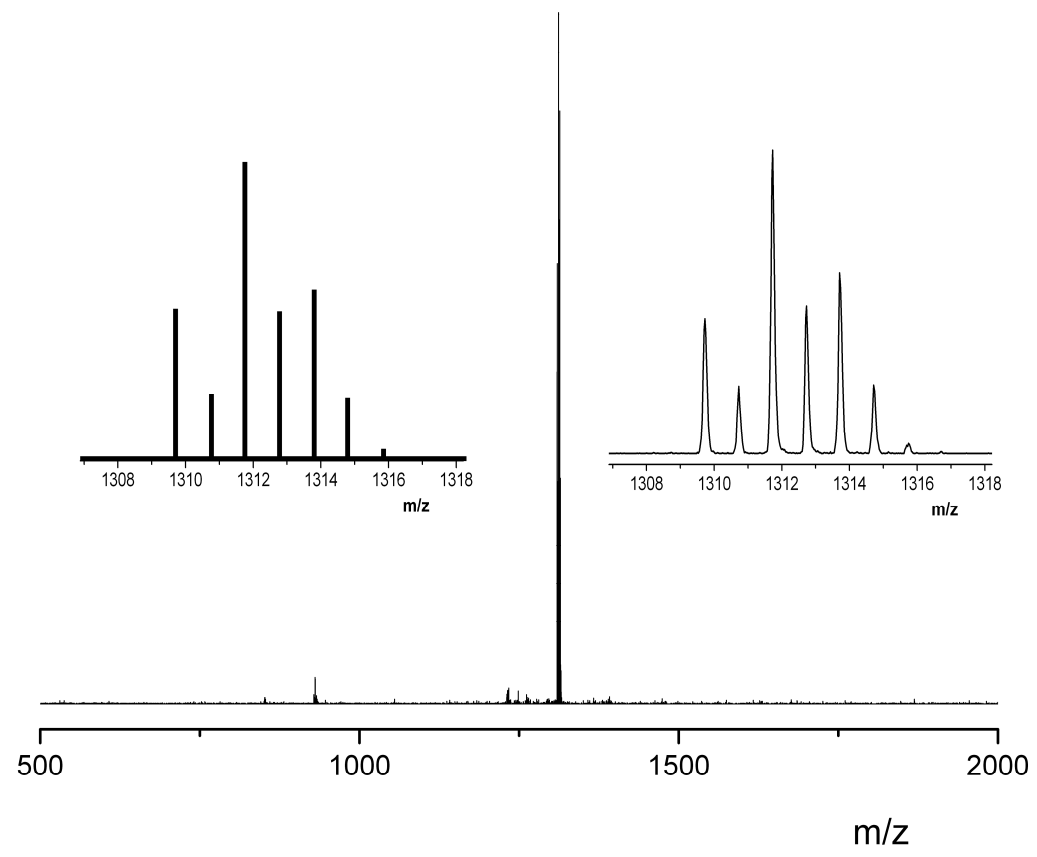



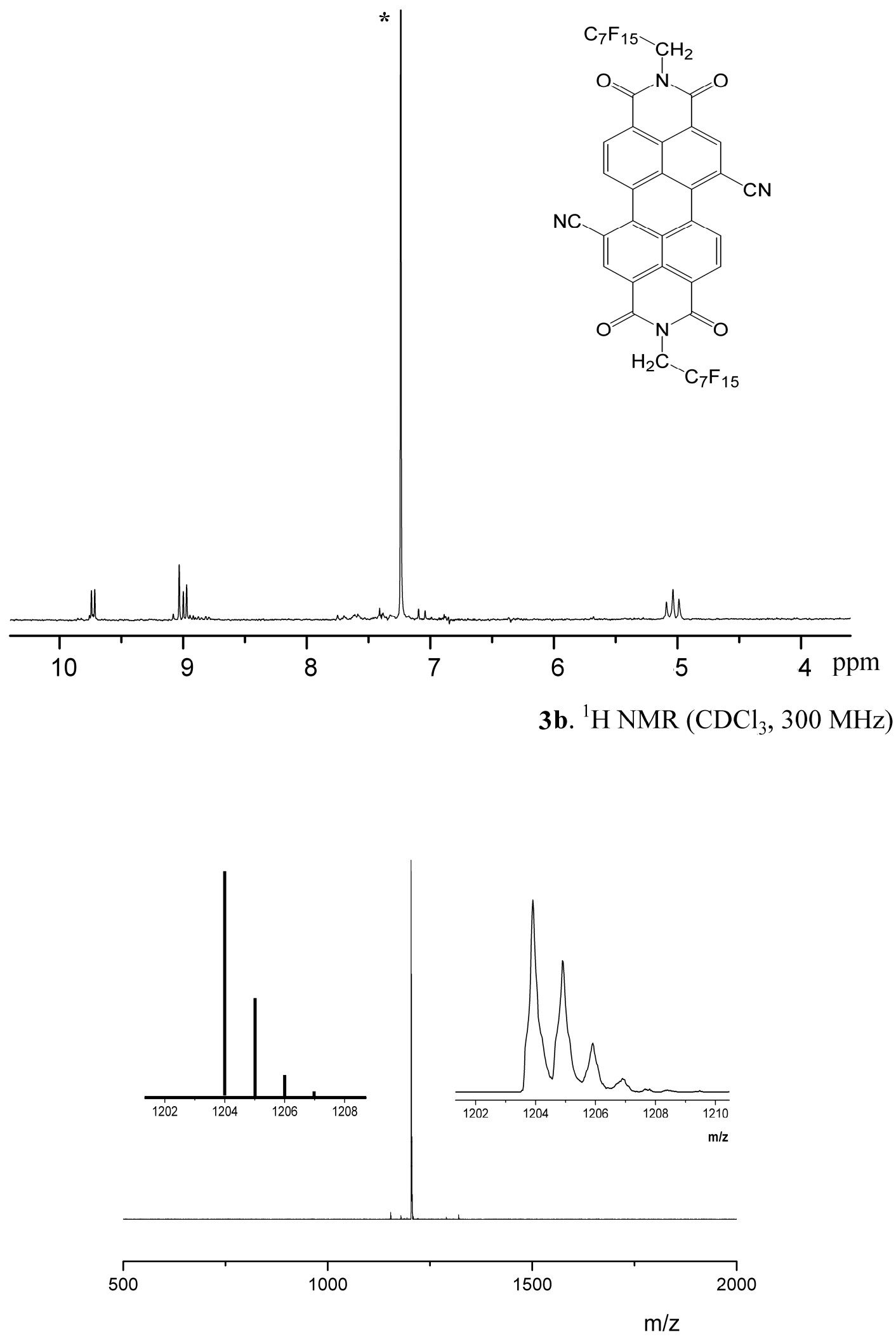


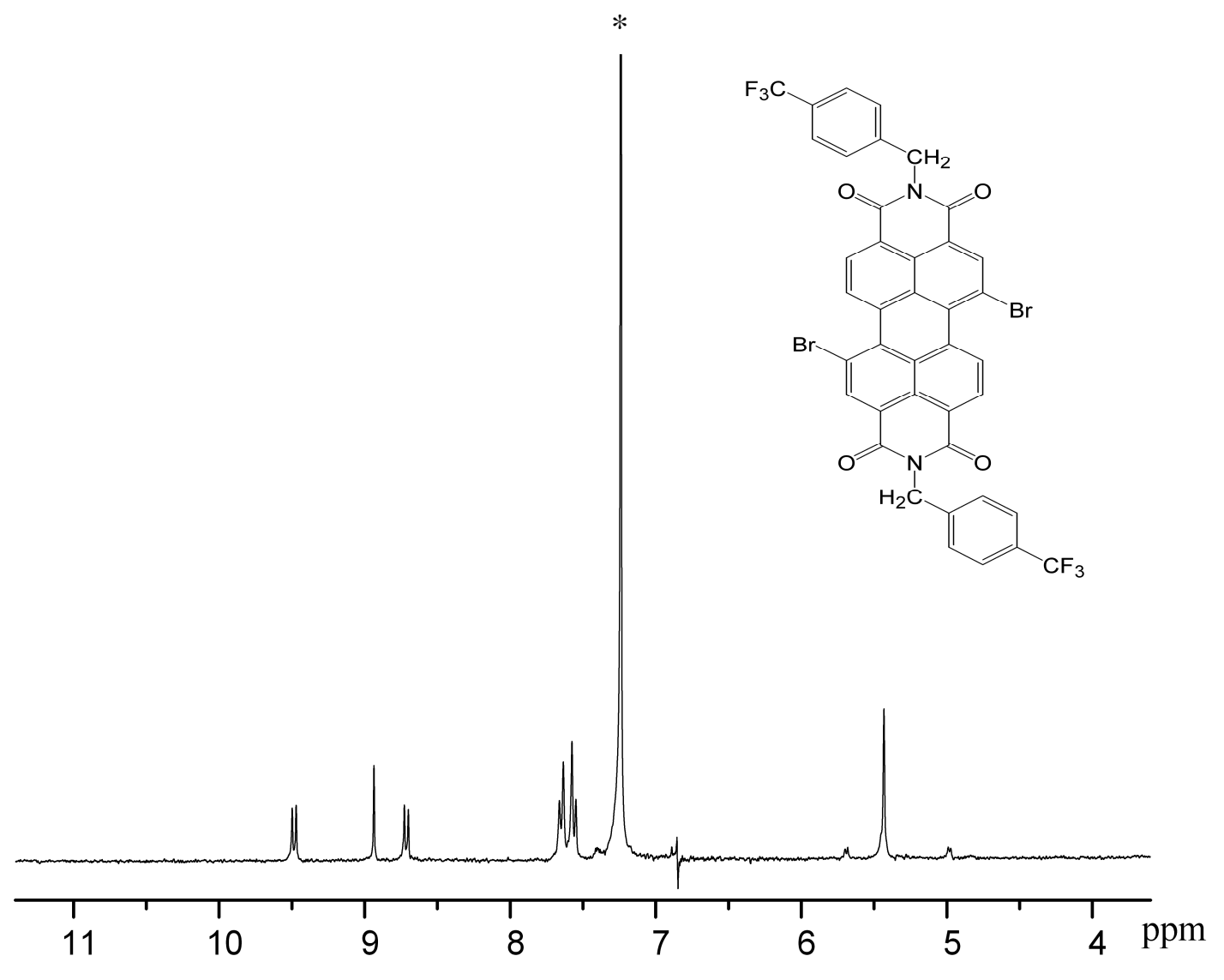

4a. ${ }^{1} \mathrm{H}$ NMR $\left(\mathrm{CDCl}_{3}, 300 \mathrm{MHz}\right)$

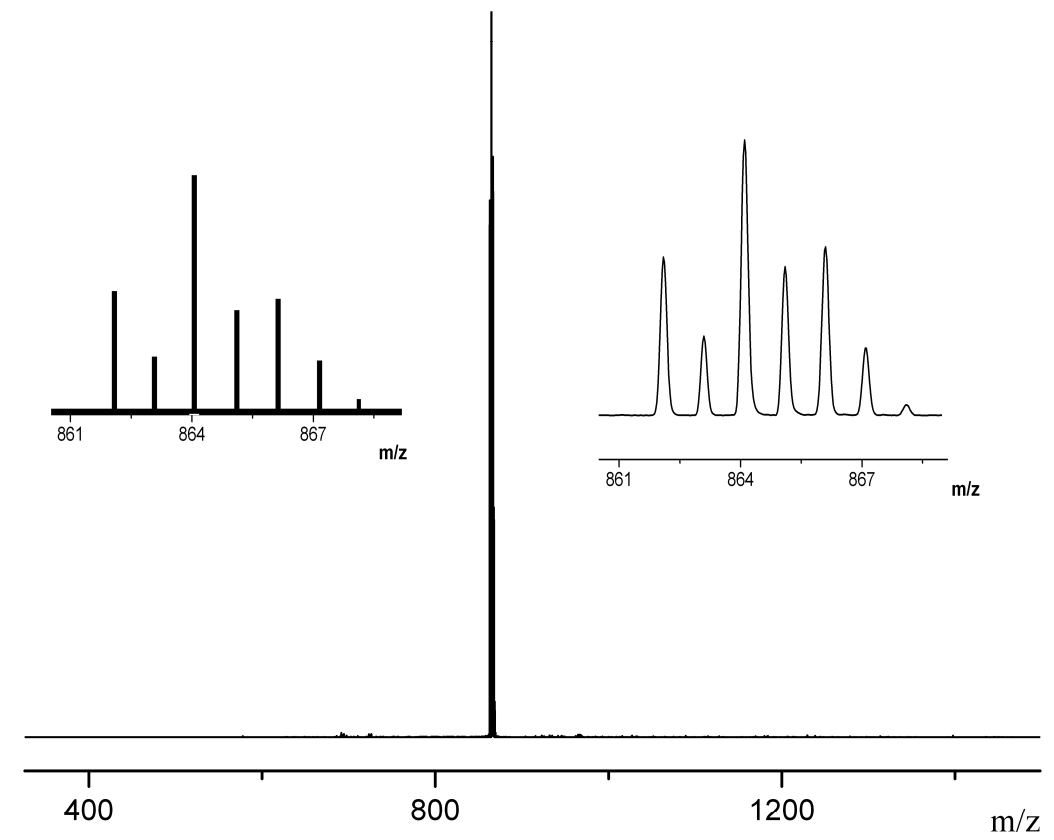




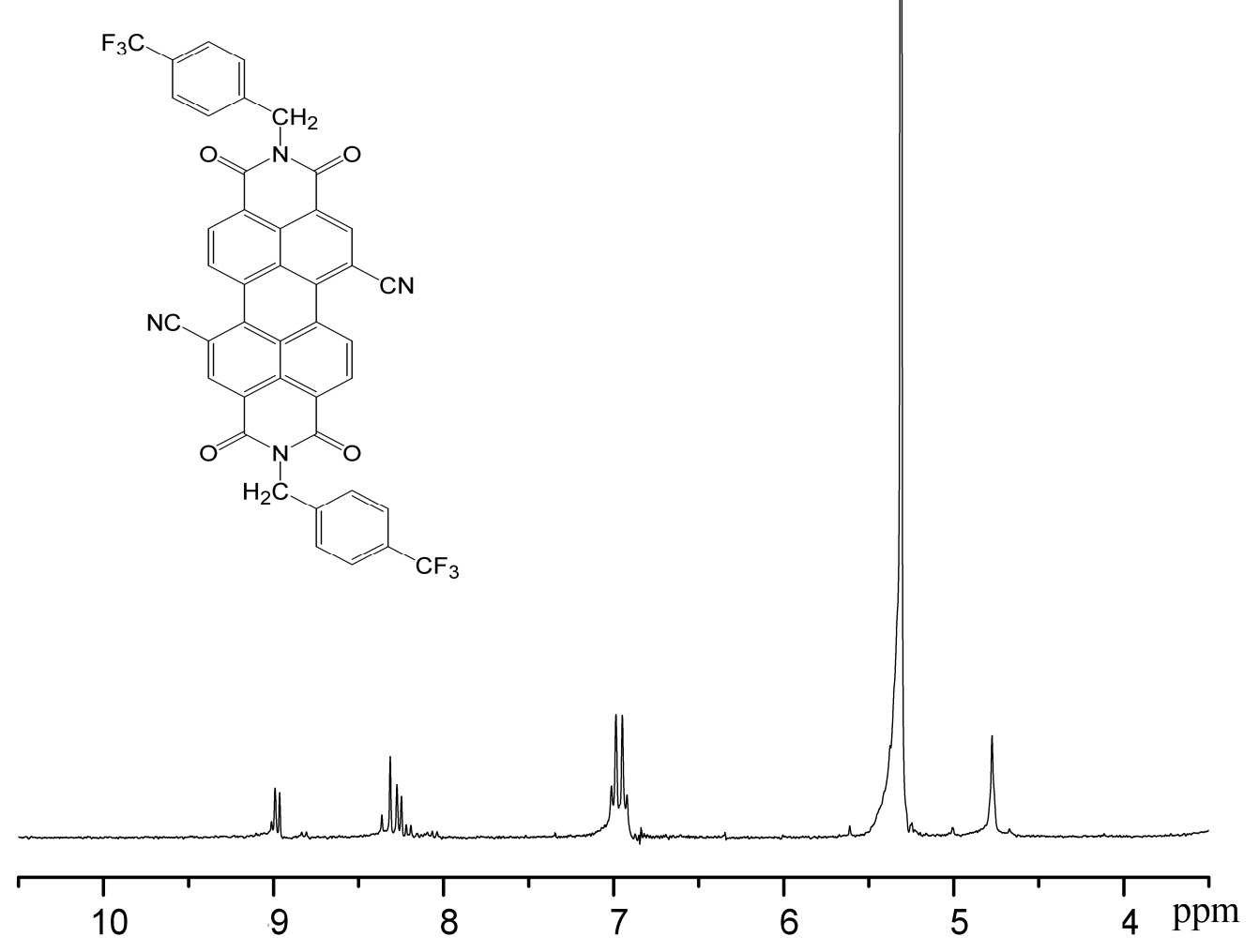

4b. ${ }^{1} \mathrm{H}$ NMR $\left(\mathrm{C}_{2} \mathrm{D}_{2} \mathrm{Cl}_{4}, 300 \mathrm{MHz}\right)$

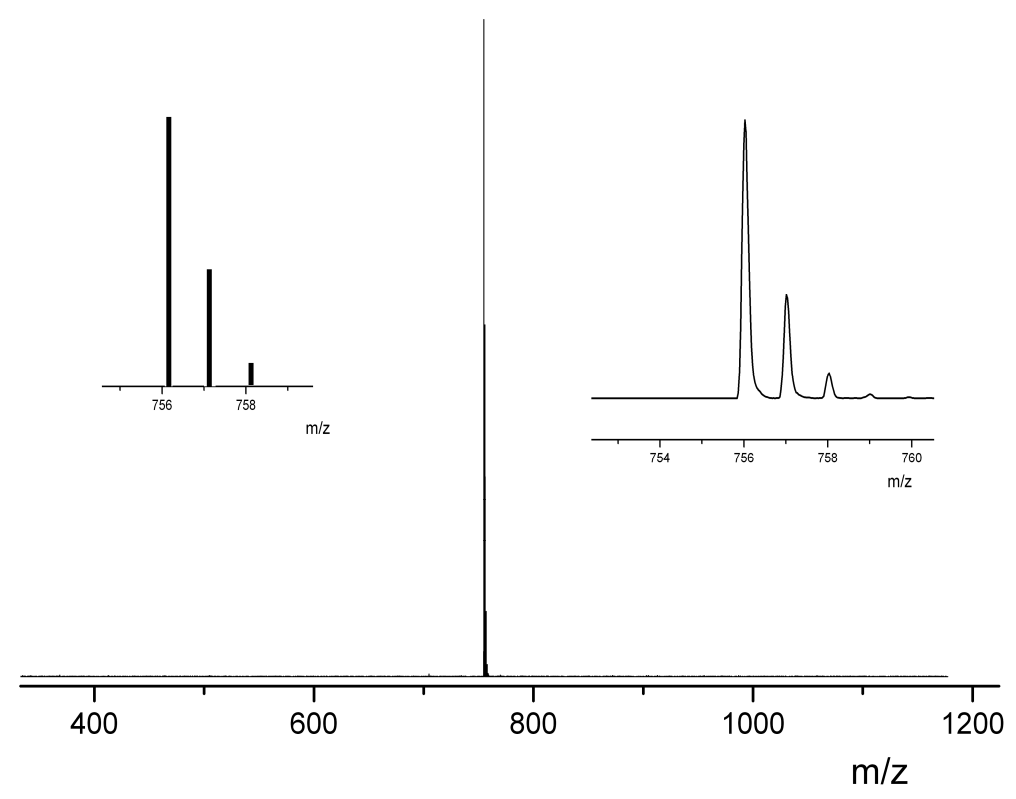




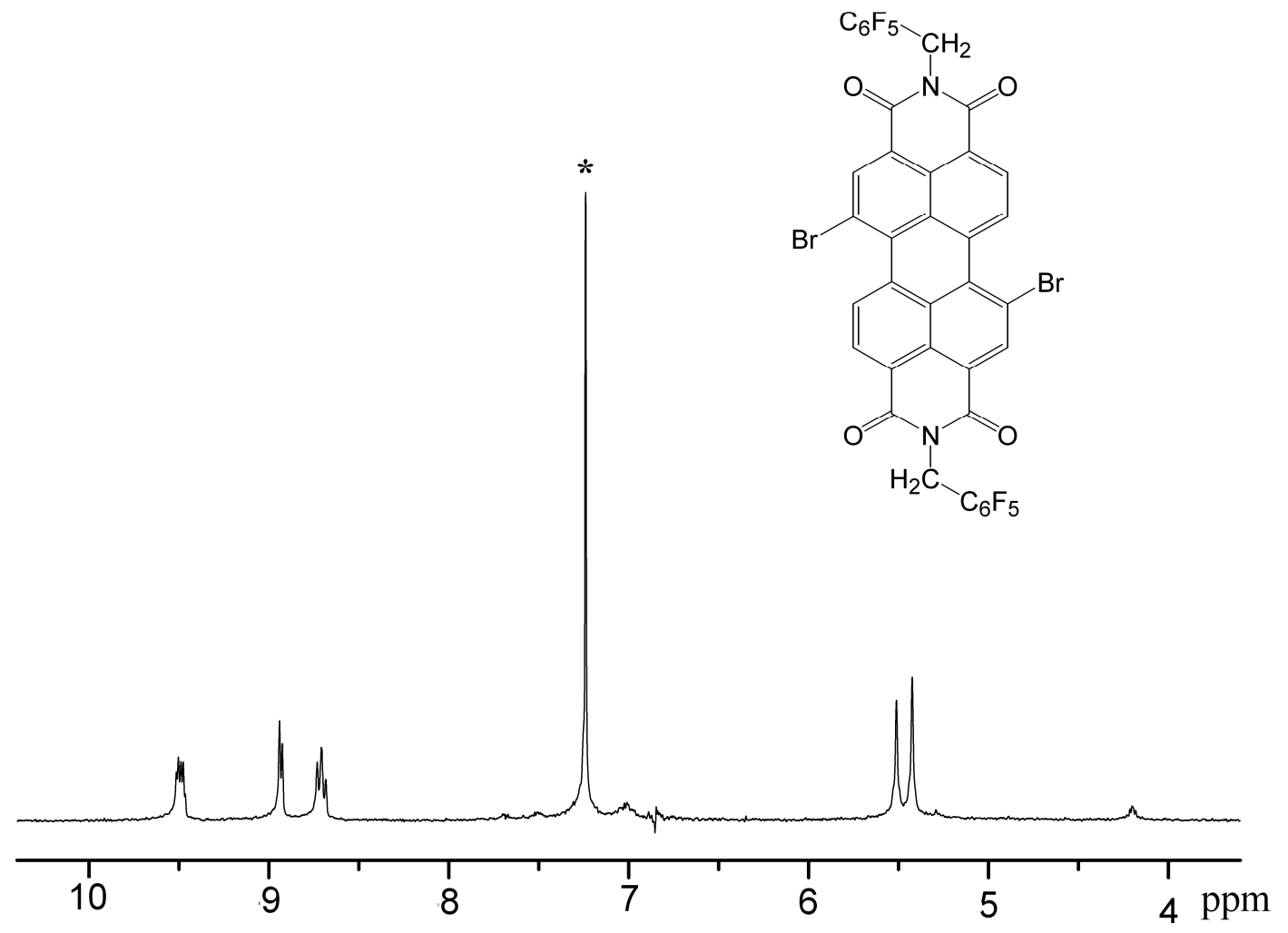

5a. ${ }^{1} \mathrm{H}$ NMR $\left(\mathrm{CDCl}_{3}, 300 \mathrm{MHz}\right)$

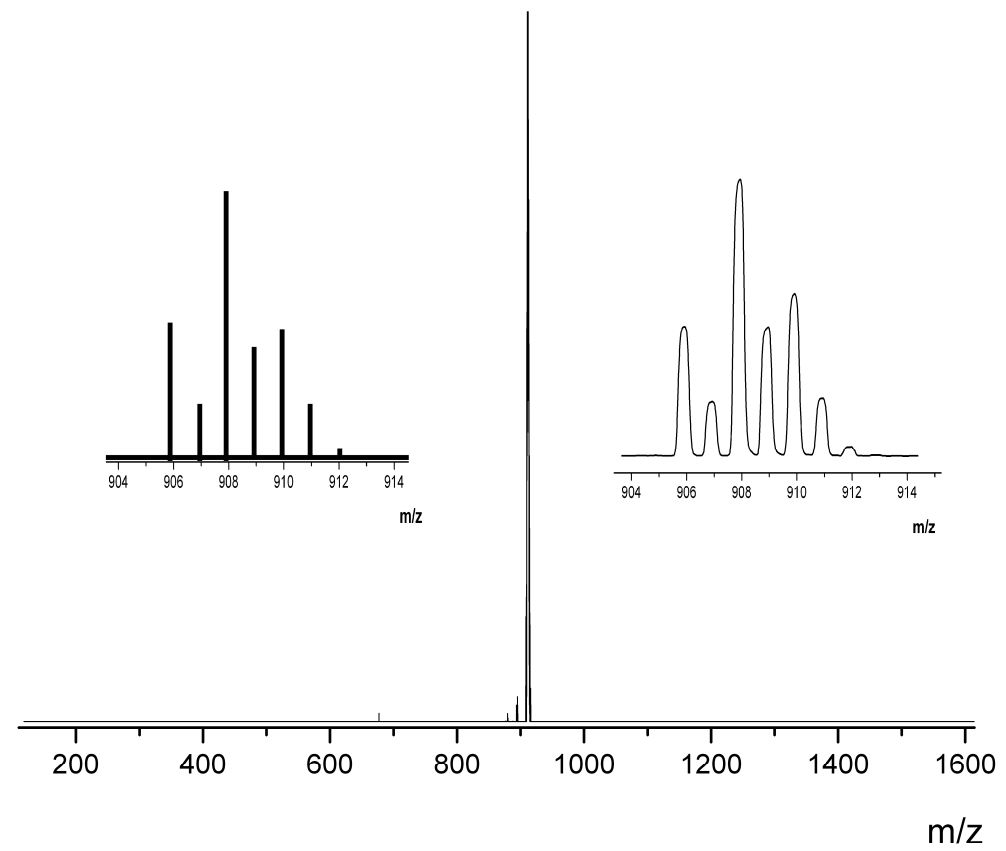




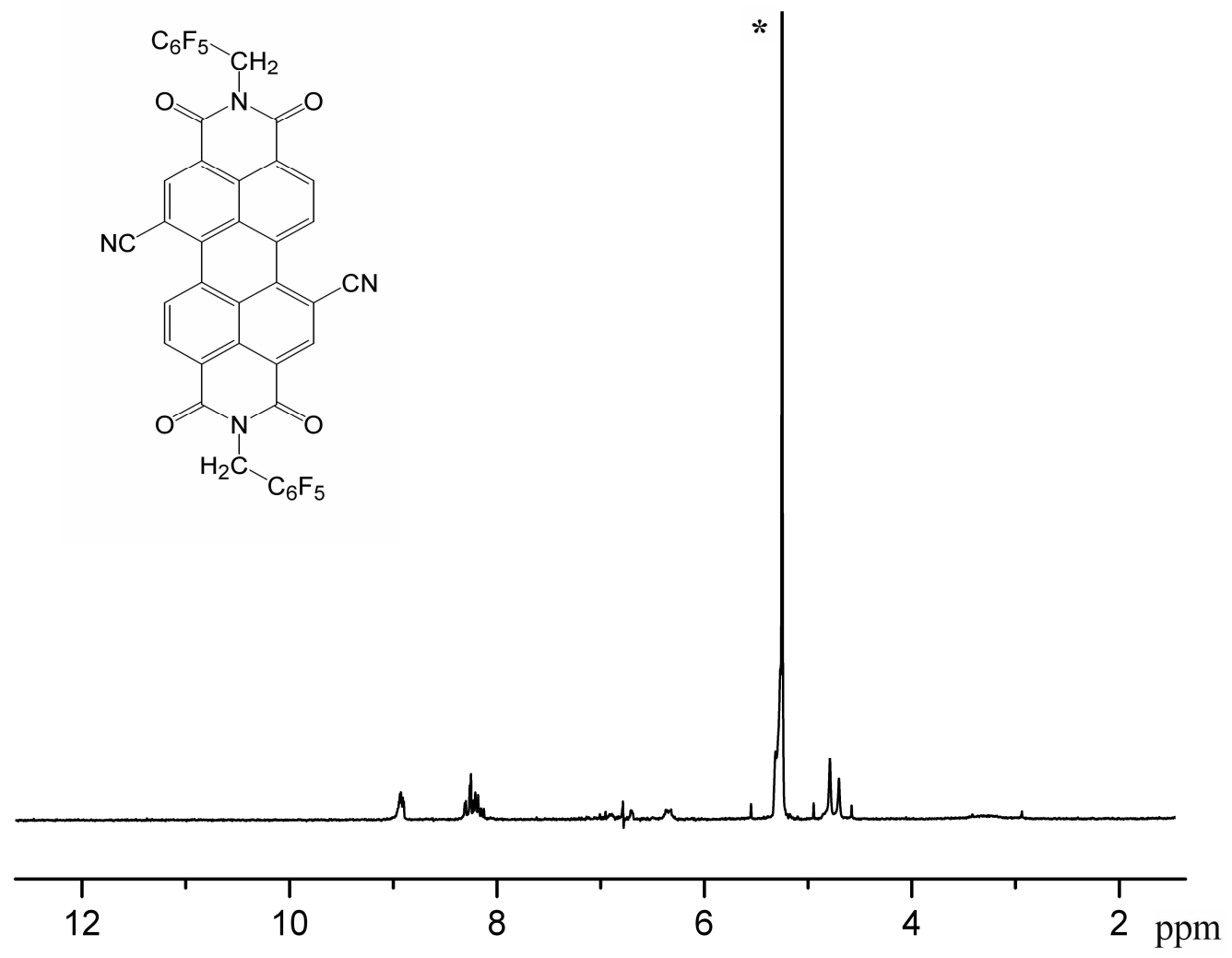

5b. ${ }^{1} \mathrm{H}$ NMR $\left(\mathrm{C}_{2} \mathrm{D}_{2} \mathrm{Cl}_{4}, 300 \mathrm{MHz}\right)$

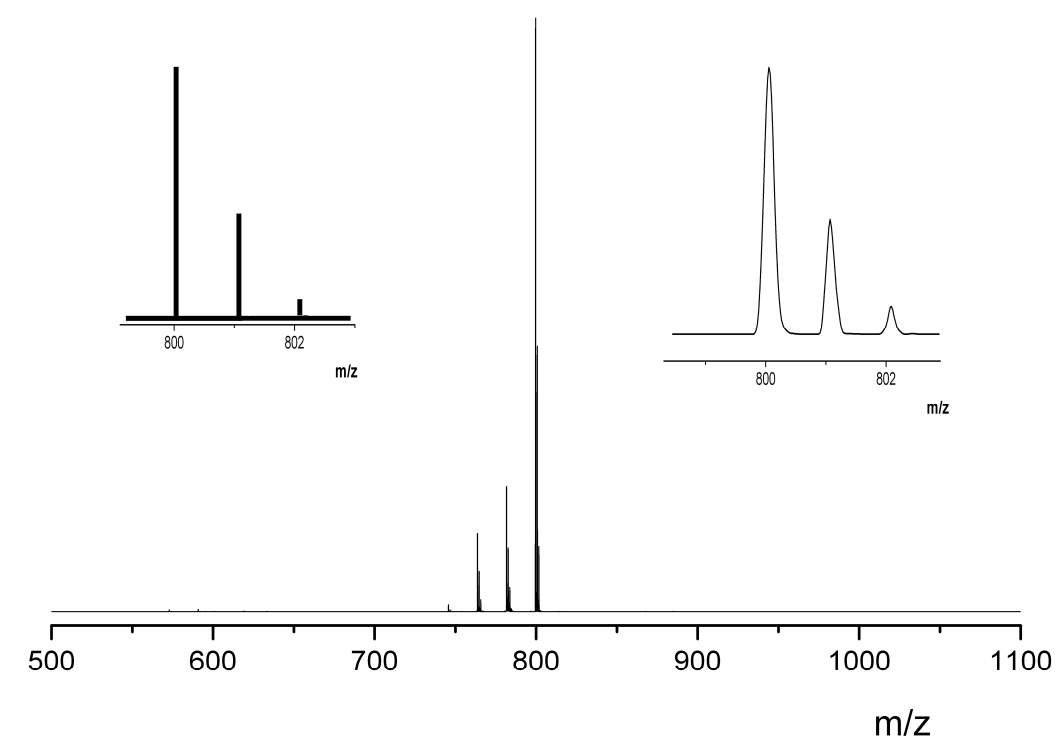

